06

\title{
Структурные превращения в борате железа при высокотемпературном отжиге
}

\author{
(C) С.В. Ягупов, ${ }^{1}$ Н.И. Снегирёв, ${ }^{1}$ К.А. Селезнева, ${ }^{1}$ Е.Т. Милюкова, ${ }^{1}$ Ю.А. Могиленец, \\ Ю.В. Ермолаев, ${ }^{2}$ М.Б. Стругацкий ${ }^{1, \uparrow}$ \\ ${ }^{1}$ Физико-технический институт, Крымский федеральный университет им. В.И. Вернадского, \\ 295007 Симферополь, Россия \\ ${ }^{2}$ Казахский Национальный исследовательский технический университет им. К.И. Сатпаева, \\ 050013 Алматы, Казахстан \\ ฯ e-mail: strugatskymb@cfuv.ru
}

Поступило в Редакцию 19 июля 2018 г.

В окончательной редакции 19 июля 2018 г.

Принято к публикации 11 марта 2019 г.

Методом растровой электронной микроскопии и рентгеноструктурного анализа исследованы морфология поверхности и кристаллическая структура бората железа, $\mathrm{FeBO}_{3}$, отожженного при различных температурах. Определены температурные пределы, при которых борат железа является структурно стабильным. Установлено, что при температурах $800-900^{\circ} \mathrm{C}$ происходит перекристаллизация в фазу ортобората железа $\mathrm{Fe}_{3} \mathrm{BO}_{6}$; свыше $900^{\circ} \mathrm{C}$ - в фазу гематита $\alpha-\mathrm{Fe}_{2} \mathrm{O}_{3}$.

Ключевые слова: борат железа, высокотемпературный отжиг, ортоборат, гематит, рентгеноструктурный анализ.

DOI: $10.21883 / J T F .2019 .08 .47896 .285-18$

\section{Введение}

Борат железа, $\mathrm{FeBO}_{3}$, представляет собой известный кристалл, являющийся „прозрачным магнетиком“ материалом, сочетающим магнитный порядок и высокую прозрачность в видимом диапазоне [1]. Исследовательский интерес к $\mathrm{FeBO}_{3}$ обусловлен уникальными магнитными, магнитоакустическими, магнитооптическими, резонансными и другими свойствами этого материала [2-4].

$\mathrm{FeBO}_{3}$ имеет структуру кальцита, пространственная группа симметрии $D_{3 d}^{6}$. C точки зрения магнитной структуры борат железа является низкотемпературным антиферромагнетиком (температура Нееля $75^{\circ} \mathrm{C}$ ) со слабым ферромагнетизмом и магнитной анизотропией типа „легкая плоскость“ [5].

Ортоборат $\mathrm{Fe}_{3} \mathrm{BO}_{6}$ - другая кристаллическая форма бората железа, изоструктурная норбергиту, символ Шенфлиса $-D_{2 h}$ [6]. Наиболее распространенная кристаллическая форма оксида железа - гематит $\alpha-\mathrm{Fe}_{2} \mathrm{O}_{3}-$ принадлежит к группе симметрии $D_{3 d}$, однако в отличие от бората железа она изоструктурна корунду [7].

Борат железа может быть синтезирован двумя основными способами: газотранспортным и растворрасплавным. Первый способ позволяет получать объемные кристаллы с хорошо развитыми небазисными гранями [8]; второй - высококачественные образцы в виде тонких базисных пластинок, ортогональных тройной оси [9].

Борат железа является весьма перспективным материалом для высокотехнологичных практических применений в различных областях науки и техники. В частности, на основе $\mathrm{FeBO}_{3}$ могут быть созданы магнитооптические и магнитоакустические преобразователи, приборы для измерения сверхслабых магнитных полей, температуры и давления. Борат железа может быть применен в современных литий-ионных батареях, позволяя существенно увеличить их емкость [10-12]. На небазисных гранях объемных монокристаллов бората железа обнаружена ЦМД-структура [13]. Этот факт свидетельствует о возможности рассматривать поверхность бората железа в качестве элемента магнитной памяти с большой плотностью записи. Кроме того, в последнее время открываются многообещающие перспективы применения высокосовершенных монокристаллов бората железа в качестве идеальных монохроматоров для выделения из „белого“ высокоинтенсивного синхротронного излучения интервала с энергией, соответствующей мессбауэровскому резонансу $[14,15]$. В этом случае к кристаллическому совершенству образцов предъявляются чрезвычайно высокие требования, достижение которых связано с решением сложных технологических задач. Классической и весьма эффективной методикой устранения напряжений и дефектов кристаллической решетки, возникающих в процессе синтеза, является отжиг монокристаллических образцов. При этом принципиально важным оказывается выбор температурного диапазона, в котором отжигаемый образец остается структурно стабильным. Выход за пределы этого температурного диапазона может привести к трансформации кристалла, в частности, в другие кристаллические фазы - к твердофазному синтезу. Таким образом, отжиг представляет и самостоятельный научный интерес как метод трансформации кристаллических фаз. 
В работе Жуберта с соавторами [16] образцы бората железа отжигались в закрытой системе в воздушной среде. Согласно данным дифференциального термического анализа [16], борат железа не претерпевает структурных изменений в результате отжига при температурах до $900^{\circ} \mathrm{C}$, выше которых происходит его разложение на оксид бора $\mathrm{B}_{2} \mathrm{O}_{3}$ и оксид железа $\mathrm{Fe}_{2} \mathrm{O}_{3}$. В случае дальнейшей длительной выдержки и гомогенизации компонент разложения возможно образование ортобората железа, $\mathrm{Fe}_{3} \mathrm{BO}_{6}$, как продукта твердофазного синтеза $[16,17]$.

При этом необходимо отметить, что эксперименты по отжигу [16] проводились на поликристаллических образцах, синтезированных из твердой фазы и, вероятно, не обладающих достаточной фазовой чистотой. Настоящая работа посвящена детальному исследованию воздействия высокотемпературного отжига на трансформацию кристаллической структуры монокристаллических образцов бората железа, $\mathrm{FeBO}_{3}$, синтезированных нами раствор-расплавным методом.

\section{Экспериментальная часть}

Экспериментальные образцы $\mathrm{FeBO}_{3}$ были синтезированы раствор-расплавным методом [9] и представляли собой шестиугольные пластинки размером в несколько миллиметров в базисной плоскости и толщиной порядка $0.1 \mathrm{~mm}$.

Проведена серия экспериментов по отжигу кристаллов в температурном диапазоне от 600 до $1100^{\circ} \mathrm{C}$. Отжиг проводился в воздушной среде с временем выдержки от 15 до $30 \mathrm{~min}$. Скорость нагрева составляла около $9^{\circ} \mathrm{C} / \mathrm{min}$. Для отжига использовалась установка, основой которой являлась программно-управляемая миниатюрная печь, оборудованная средствами оптической микроскопии с видеофиксацией. Объектив был отделен от шахты печи специально изготовленным экраном из отполированного монокристалла корунда. Такое решение позволило в реальном времени наблюдать за состоянием образца в процессе отжига. Образец помещался непосредственно на спае S-термопары.

Фазовый состав образцов определялся методом порошков на рентгеновском дифрактометре PANalytical X'PertPro MPD с использованием $\mathrm{Cu} K_{\alpha}$-излучения. Обработка экспериментальных данных проводилась с помощью HighScorePlus (ICC Database) [18]. Морфология поверхности отожженных образцов исследовалась путем сканирования растровым электронным микроскопом РЭМ-106. С целью отвода накопленного заряда исследуемые образцы фиксировались на алюминиевом предметном столике электронного микроскопа с помощью специальной проводящей клейкой ленты на основе графита.

\section{Результаты и обсуждение}

Образцы, отожженные в температурном диапазоне ниже $800^{\circ} \mathrm{C}$, не обладали видимыми отличиями от ис-
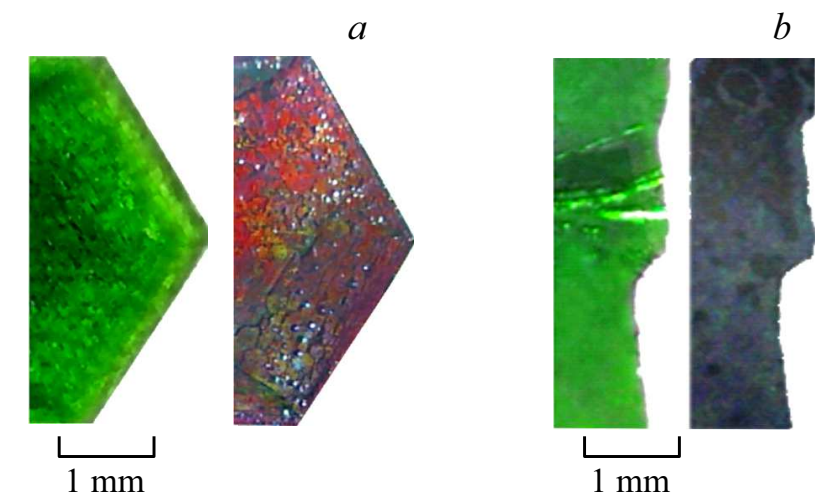

Рис. 1. Монокристаллы бората железа до (слева) и после (справа) отжига при $830^{\circ} \mathrm{C}(a)$ и $1010^{\circ} \mathrm{C}(b)$.
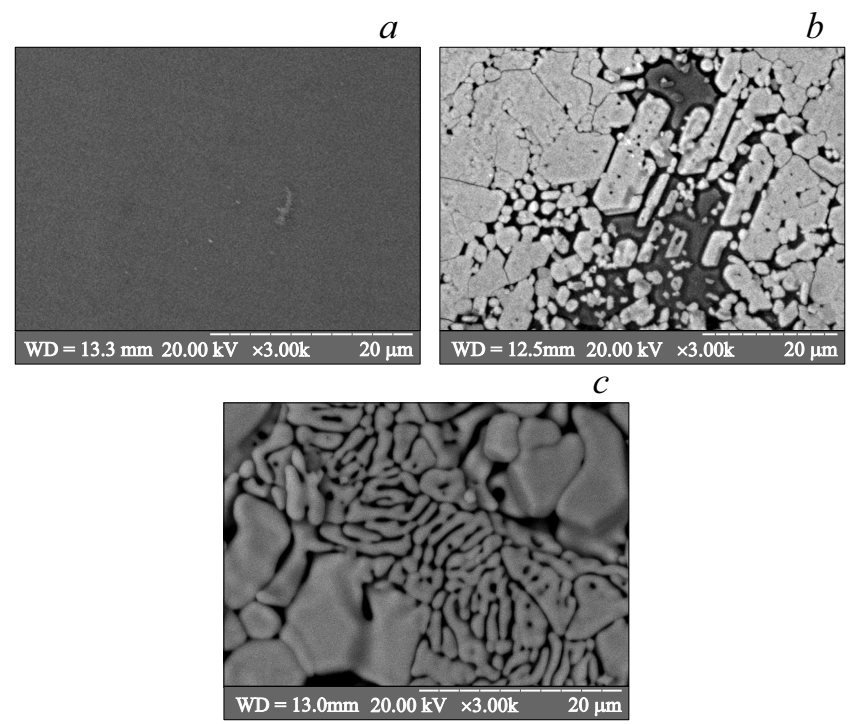

Рис. 2. Изображения поверхности образцов до отжига $(a)$, отожженных при $830^{\circ} \mathrm{C}(b)$ и $1010^{\circ} \mathrm{C}(c)$, полученные с помощью РЭМ.

ходного состояния; кристаллы, отожженные в диапазоне 800-900 ${ }^{\circ}$, приобретали нехарактерный для бората железа бурый цвет (рис. 1,a). После отжига при более высоких температурах $\left(900-1100^{\circ} \mathrm{C}\right)$ образцы имели темный цвет и явный металлический блеск (рис. $1, b)$.

В ходе проведения РЭМ-сканирования монокристаллов обнаружено, что поверхность образцов, изначально гладкая и не имеющая включений (рис. 2,a), после отжига при $830^{\circ} \mathrm{C}$ претерпевала структурные изменения в виде появления поверхностного слоя, отдельные элементы которого могли идентифицироваться как шестиугольные и прямоугольные кристаллиты (рис. 2, b), характерные для фаз $\mathrm{FeBO}_{3}$ и $\mathrm{Fe}_{3} \mathrm{BO}_{6}$ соответственно [5,6]. Впоследствии обнаружена возможность удаления данного слоя путем кипячения образцов в $20 \%$ растворе азотной кислоты в течение 6 h. Это говорит о том, что образовавшийся поверхностный слой не образует цельной композитной структуры с основой. 


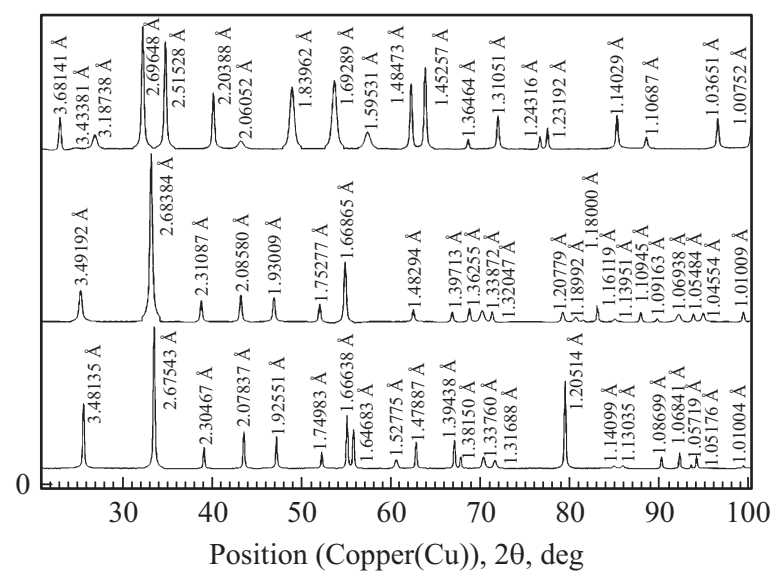

Рис. 3. Рентгеновские дифрактограммы бората железа (нижняя линия), а также бората железа, отожженного при $830^{\circ} \mathrm{C}$ (средняя линия) и при $1010^{\circ} \mathrm{C}$ (верхняя линия).

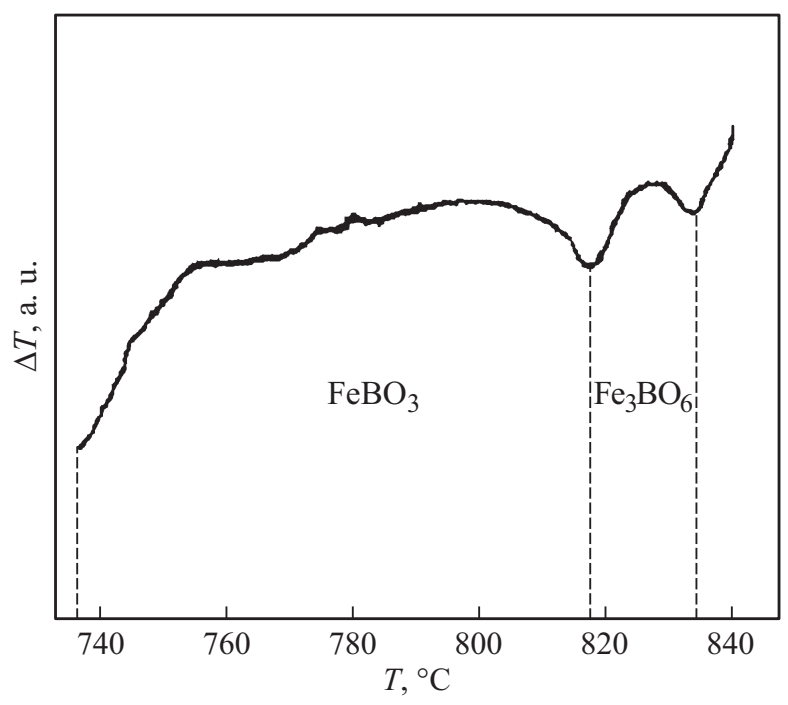

Рис. 4. Участки кривой ДТА для системы $\mathrm{Fe}_{2} \mathrm{O}_{3}-\mathrm{B}_{2} \mathrm{O}_{3}-\mathrm{PbO}-$ $\mathrm{PbF}_{2}[9]$.

Подобные кристаллиты наблюдались и на поверхности образцов, отожженных при температуре $1010^{\circ} \mathrm{C}$ (рис. 2,c). Однако поверхность этих образцов имела более выраженные структурные изменения.

На рис. 3 представлены рентгеновские дифрактограммы бората железа, а также бората железа, отожженного при различных температурах. Согласно данным рентгеноструктурного анализа (РСА), после отжига при температуре $830^{\circ} \mathrm{C}$ в образцах, помимо $\mathrm{FeBO}_{3}$, обнаруживается фаза $\mathrm{Fe}_{3} \mathrm{BO}_{6}$; в образцах, отожженных при $1010^{\circ} \mathrm{C}$, преобладает фаза $\alpha-\mathrm{Fe}_{2} \mathrm{O}_{3}$, а также присутствуют следы фаз $\mathrm{FeBO}_{3}$ и $\mathrm{Fe}_{3} \mathrm{BO}_{6}$. Эти структурные изменения связаны с потерей оксида бора в процессе инконгруэнтного плавления бората железа, что демонстрируют уравнения:

$$
4 \mathrm{FeBO}_{3} \stackrel{830^{\circ}}{\longrightarrow} 2 \mathrm{Fe}_{3} \mathrm{BO}_{6}+2 \mathrm{~B}_{2} \mathrm{O}_{3} \stackrel{1010^{\circ}}{\longrightarrow} 3 \mathrm{Fe}_{2} \mathrm{O}_{3}+3 \mathrm{~B}_{2} \mathrm{O}_{3}
$$

Обратим внимание, что в работе [19] представлены сведения о том, что борат железа остается структурно стабильным до температур $910^{\circ} \mathrm{C}$. Однако авторы [19] не приводят информации о деталях эксперимента.

Интересным представляется тот факт, что температурный диапазон образования фазы $\mathrm{Fe}_{3} \mathrm{BO}_{6}$ в процессе инконгруэнтного плавления бората железа является схожим с температурным диапазоном растворрасплавного синтеза кристаллов в системе $\mathrm{Fe}_{2} \mathrm{O}_{3}-\mathrm{B}_{2} \mathrm{O}_{3}-$ $\mathrm{PbO}-\mathrm{PbF}_{2}$ [9]. На рис. 4 представлены результаты термических исследований этой системы, в которой были выращены экспериментальные образцы.

\section{Заключение}

Проведена серия экспериментов по высокотемпературному отжигу монокристаллов бората железа. Образцы, отожженные при различных температурах, исследовались методами РЭМ и РСА. В результате установлено, что при высокотемпературном отжиге монокристаллов бората железа в их структуре наступают необратимые изменения, связанные с образованием новых кристаллических фаз. При температурах $800-900^{\circ} \mathrm{C}$ происходит перекристаллизация в фазу ортобората железа $\mathrm{Fe}_{3} \mathrm{BO}_{6}$; свыше $900^{\circ} \mathrm{C}$ - в фазу гематита $\alpha-\mathrm{Fe}_{2} \mathrm{O}_{3}$. Трансформация кристаллических фаз начинается на поверхности и распространяется вглубь кристалла.

\section{Финансирование работы}

Исследование выполнено при финансовой поддержке РФФИ в рамках научного проекта № 18-32-00210 мол_а (изучение влияния высокотемпературного отжига на кристаллическую структуру бората железа), а также в рамках Программы развития ФГАОУ ВО „Крымский федеральный университет им. В.И. Вернадского“ на 2015-2024 гг.

\section{Конфликт интересов}

Авторы заявляют, что у них нет конфликта интересов.

\section{Список литературы}

[1] Edelman I., Kliava J. // Phys. Stat. Sol. B. 2009. Vol. 246. P. 2216-2231.

[2] Afanasiev D., Razdolski I., Skibinsky K.M., Bolotin D., Yagupov S.V., Strugatsky M., Kirilyuk A., Rasing Th., Kimel A.V. // Phys. Rev. Lett. 2014. Vol. 112. P. 147403-1-5.

[3] Eibshütz M., Lines M. // Phys. Rev. B. 1973. Vol. 7. P. 4907-4915.

[4] Glazkov V., Kichanov S., Kozlenko D., Savenko B., Somenkov V. // J. Magn. Magn. Mater. 2003. Vol. 258. P. $543-$ 544.

[5] Diehl R., Jantz W., Nolang B.I., Wettling W. // Current Topics in Mater. Sci. 1984. Vol. 11. P. 241-387.

[6] White J.G., Miller A., Nielsen R.E. // Acta Cryst. 1965. Vol. 19. P. 1060-1061. 
[7] Rollmann G., Rohrbach A., Entel P., Hafner J. // Phys. Rev. B. 2004. Vol. 69. P. 165107-1-12.

[8] Панкратов А., Стругацкий М., Ягупов С. // Ученые записки Таврического национального ун-та. Физика. 2007. T. 20 (59). № 1. C. 64-73.

[9] Yagupov S., Strugatsky M., Seleznyova K., Maksimova E., Nauhatsky I., Yagupov V., Milyukova E., Kliava J. // Appl. Phys. A. 2015. Vol. 121. P. 179-185.

[10] Rowsell J.L., Gaubicher J., Nazar L. // J. Power Sources. 2001. Vol. 97-98. P. 254-257.

[11] Shigeto Okada, Toshiyuki Tonuma, Yasushi Uebo, Junichi Yamaki // J. Power Sources. 2003. Vol. 119-121. P. $621-625$.

[12] Ibarra-Palos A., Darie C., Proux O., Hazemann J.L., Aldon L., Jumas J.C., Morcrette M., Strobel P. // Chem. Mater. 2002. Vol. 14. P. 1166.

[13] Zubov V.E., Krinchik G.S., Seleznyov V.N., Strugatsky M.B. // J. Magn. Magn. Mater. 1990. Vol. 86. P. 105-114.

[14] Potapkin V., Chumakov A.I., Smirnov G.V., Celse J.-P., Rüffer R., McCammon C., Dubrovinsky L. // J. Synchrotron Radiation. 2012. Vol. 19. P. 559-569.

[15] Potapkin V., Chumakov A.I., Smirnov G.V., Rüffer R., McCammon C., Dubrovinsky L. // Phys. Rev. A. 2012. Vol. 86. P. 053808-1-5.

[16] Joubert J.C., Shirk T., White W.B., Roy R. // Mat. Res. Bull. 1968. Vol. 3. P. 671-676.

[17] Makram H., Touron L., Loriers J. // J. Crystal Grown. 1972. Vol. 13-14. P. 595-587.

[18] Inorganic Crystal Structure Database [электронный ресурс] FIZ Karlsruhe. 1997. URL: icsd.fiz-karlsruhe.de

[19] Зверева Р.И., Духовская Е.Л., Сапожников Ю.Л. // Известия АН СССР. Неорганические материалы. 1975. Т. 11. № 2. C. 282-284. 